\title{
Best proximity points for generalized $\alpha$ - $\phi$-Geraghty proximal contraction mappings and its applications
}

\author{
Javad Hamzehnejadi and Rahmatollah Lashkaripour ${ }^{*}$
}

\section{"Correspondence:}

lashkari@hamoon.usb.ac.ir Department of Mathematics, University of Sistan and

Baluchestan, Zahedan, Iran

\begin{abstract}
In this paper, we introduce the new notion of generalized $\alpha-\phi$-Geraghty proximal contraction mappings and investigate the existence of the best proximity point for such mappings in complete metric spaces. The obtained results extend, generalize, and complement some known fixed and best proximity point results from the literature.
\end{abstract}

MSC: $47 \mathrm{H} 10 ; 54 \mathrm{H} 25 ; 11 \mathrm{~J} 83$

Keywords: best proximity point; generalized $\alpha$ - $\phi$-Geraghty proximal contraction mapping; Geraghty contraction mapping; fixed point

\section{Introduction}

Let $A$ and $B$ be two nonempty subsets of a metric space $(X, d)$. An element $x \in A$ is said to be a fixed point of a given map $T: A \rightarrow B$ if $T x=x$. Clearly, $T(A) \cap A \neq \emptyset$ is a necessary (but not sufficient) condition for the existence of a fixed point of $T$. If $T(A) \cap A=\emptyset$, then the set of fixed points of $T$ is empty. In such a situation, one often attempts to find an element $x$ which is in some sense closest to $T x$. Best approximation theory and best proximity point analysis have been developed in this direction. Let $A \cap B=\emptyset$ and $T: A \rightarrow B$ be a non-selfmapping. A best proximity point of the mapping $T$ is a point $x^{*} \in A$ satisfying the equality $d\left(x^{*}, T x^{*}\right)=d(A, B)$, where $d(A, B)=\inf \{d(x, y): x \in A, y \in B\}$. The goal of best proximity point theory is to furnish sufficient conditions that ensure the existence of best proximity points. An operator $T: A \cup B \rightarrow A \cup B$ is said to be a cyclic contraction if $T(A) \subseteq B$ and $T(B) \subseteq A$ and there exists $k \in(0,1)$ such that

$$
d(T x, T y) \leq k d(x, y)+(1-k) d(A, B), \quad \text { for all } x \in A, y \in B
$$

A best proximity point theorem for cyclic contraction mappings has been detailed by Anthony and Veeramani [1]. A great number of generalizations of this theorem appear in the literature. For more details of this approach, we refer the reader to [2-7]. We introduce the class $\mathcal{F}$ of those functions $\beta:[0, \infty) \rightarrow[0,1)$ satisfying the following condition:

$$
\beta\left(t_{n}\right) \rightarrow 1 \text { implies } t_{n} \rightarrow 0 .
$$

(c) 2016 Hamzehnejadi and Lashkaripour. This article is distributed under the terms of the Creative Commons Attribution 4.0 International License (http://creativecommons.org/licenses/by/4.0/), which permits unrestricted use, distribution, and reproduction in any medium, provided you give appropriate credit to the original author(s) and the source, provide a link to the Creative Commons license, and indicate if changes were made. 
Recently, Karapinar [8] introduced a new class of contraction mappings called generalized $\alpha-\phi$-Geraghty contraction type mappings. Let $\Phi$ denote the class of all functions $\phi:[0, \infty) \rightarrow[0, \infty)$ which satisfy the following conditions:
(a) $\phi$ is nondecreasing;
(b) $\phi$ is continuous;
(c) $\phi(t)=0 \Leftrightarrow t=0$.

Definition 1.1 ([8]) Let $(X, d)$ be a metric space, and let $\alpha: X \times X \rightarrow[0, \infty)$ be a function. A mapping $T: X \rightarrow X$ is said to be a generalized $\alpha$ - $\phi$-Geraghty contraction if there exists $\beta \in \mathcal{F}$ such that for all $x, y \in X$

$$
\alpha(x, y) \phi(d(T x, T y)) \leq \beta(\phi(M(x, y))) \phi(M(x, y))
$$

where $\phi \in \Phi$ and

$$
M(x, y)=\max \{d(x, y), d(x, T x), d(y, T y)\}, \quad \text { for any } x, y \in X .
$$

Let $T: X \rightarrow X$ be a mapping and $\alpha: X \times X \rightarrow[0, \infty)$ be a function. Then $T$ is said to be $\alpha$-admissible [9] if

$$
\alpha(x, y) \geq 1 \quad \text { implies } \quad \alpha(T x, T y) \geq 1 .
$$

Definition $1.2([10])$ Let $(X, d)$ be a complete metric space, $\alpha: X \times X \rightarrow[0, \infty)$ be a function, and let $T: X \rightarrow X$ be a mapping. The sequence $\left\{x_{n}\right\}$ is said to be $\alpha$-regular if $\alpha\left(x_{n}, x_{n+1}\right) \geq 1$ for all $n \in \mathbb{N}$ and $x_{n} \rightarrow x \in X$ as $n \rightarrow \infty$, implies that there exists a subsequence $\left\{x_{n_{k}}\right\}$ of $\left\{x_{n}\right\}$ such that $\alpha\left(x_{n_{k}}, x\right) \geq 1$ for all $k$.

The main result obtained in [8] is the following fixed point theorem.

Theorem 1.3 Let $(X, d)$ be a complete metric space, $\alpha: X \times X \rightarrow \mathbb{R}$ be a function, and let $T: X \rightarrow X$ be a map. Suppose that the following conditions are satisfied:

(i) $T$ is generalized $\alpha$ - $\phi$-Geraghty contraction type map;

(ii) $T$ is triangular $\alpha$-admissible;

(iii) there exists $x_{1} \in X$ such that $\alpha\left(x_{1}, T x_{1}\right) \geq 1$;

(iv) either, $T$ is continuous, or any sequence $\left\{x_{n}\right\}$ is $\alpha$-regular;

where an $\alpha$-admissible map $T$ is said to be triangular $\alpha$-admissible [9] if

$$
\alpha(x, z) \geq 1 \quad \text { and } \quad \alpha(z, y) \geq 1 \quad \text { implies } \quad \alpha(x, y) \geq 1 .
$$

Then $T$ has a fixed point $x^{*} \in X$, and $\left\{T^{n} x_{1}\right\}$ converges to $x^{*}$.

We refer the reader to [11-13] for further examples.

In this work, we extend the concept of generalized $\alpha$ - $\phi$-Geraghty contraction type mappings to generalized $\alpha-\phi$-Geraghty proximal contraction mappings to the case of non-self mappings. More precisely, we study the existence and uniqueness of best proximity points for generalized $\alpha-\phi$-Geraghty proximal contraction non-self-mappings. Several applications and interesting consequences of our obtained results are presented. 
Let $A$ and $B$ be two nonempty subsets of a metric space $(X, d)$. We denote by $A_{0}$ and $B_{0}$ the following sets:

$$
\begin{aligned}
& A_{0}=\{a \in A: d(a, b)=d(A, B) \text { for some } b \in B\}, \\
& B_{0}=\{b \in B: d(a, b)=d(A, B) \text { for some } a \in A\} .
\end{aligned}
$$

Definition 1.4 An element $x^{*} \in A$ is said to be a best proximity point of the non-selfmapping $T: A \rightarrow B$ if it satisfies the following condition:

$$
d\left(x^{*}, T x^{*}\right)=d(A, B) .
$$

We denote the set of all best proximity points of $T$ by $P_{T}(A)$, that is,

$$
P_{T}(A):=\{x \in A: d(x, T x)=d(A, B)\} .
$$

Let $A$ and $B$ be two nonempty closed subsets of metric space $(X, d)$. $B$ is said to be approximatively compact with respect to $A$ if every sequence $\left\{y_{n}\right\}$ in $B$, satisfying the condition $\lim _{n \rightarrow \infty} d\left(x, y_{n}\right)=d(x, B)$ for some $x \in A$, has a convergent subsequence.

Definition 1.5 ([10]) Let $T: A \rightarrow B$ be a map and $\alpha: X \times X \rightarrow[0, \infty)$ be a function. The mapping $T$ is said to be $\alpha$-proximal admissible if

$$
\left.\begin{array}{l}
\alpha(x, y) \geq 1 \\
d(u, T x)=d(A, B) \\
d(v, T y)=d(A, B)
\end{array}\right\} \quad \Rightarrow \quad \alpha(u, v) \geq 1
$$

for all $x, y, u, v \in A$.

\section{Main results}

We start this section with the following definition.

Definition 2.1 Let $A$ and $B$ be two nonempty subsets of metric space $(X, d)$ and $T: A \rightarrow B$ be a mapping. We say that $T$ has the $R J$-property if for any sequence $\left\{x_{n}\right\} \subseteq A$,

$$
\left.\begin{array}{l}
\lim _{n \rightarrow \infty} d\left(x_{n+1}, T x_{n}\right)=d(A, B) \\
\lim _{n \rightarrow \infty} x_{n}=x
\end{array}\right\} \Rightarrow x \in A_{0}
$$

In order to illustrate $R J$-property, we present some examples.

Example 2.2 Let $A$ and $B$ be two nonempty closed subsets of metric space $(X, d)$ and $T: A \rightarrow B$ be a continuous mapping. Let $\lim _{n \rightarrow \infty} d\left(x_{n+1}, T x_{n}\right)=d(A, B)$ and $\lim _{n \rightarrow \infty} x_{n}=x$. Since $T$ is continuous, $\lim _{n \rightarrow \infty} T x_{n}=T x$. This implies that

$$
d(x, T x)=\lim _{n \rightarrow \infty} d\left(x_{n+1}, T x_{n}\right)=d(A, B) .
$$

Therefore $x \in A_{0}$, which implies that $T$ has the $R J$-property. 
Example 2.3 Let $A$ and $B$ be two nonempty closed subsets of metric space $(X, d)$ such that $B$ is approximatively compact with respect to $A$ and $T: A \rightarrow B$ be a mapping. Let $\lim _{n \rightarrow \infty} x_{n}=x$ and $\lim _{n \rightarrow \infty} d\left(x_{n+1}, T x_{n}\right)=d(A, B)$. For any $n \in \mathbb{N}$, we have

$$
d(A, B) \leq d\left(x, T x_{n}\right) \leq d\left(x, x_{n+1}\right)+d\left(x_{n+1}, T x_{n}\right) .
$$

Thus $\lim _{n \rightarrow \infty} d\left(x, T x_{n}\right)=d(A, B)$. Also for any $n \in \mathbb{N}$, we have $d(x, B) \leq d\left(x, T x_{n}\right)$. Thus

$$
d(x, B) \leq \lim _{n \rightarrow \infty} d\left(x, T x_{n}\right)=d(A, B) \leq d(x, B),
$$

which implies that $\lim _{n \rightarrow \infty} d\left(x, T x_{n}\right)=d(x, B)$. Since $B$ is approximatively compact with respect to $A$, there exist a subsequence $\left\{x_{n_{k}}\right\} \subseteq\left\{x_{n}\right\}$ and $y \in B$ such that $\lim _{n \rightarrow \infty} T x_{n_{k}}=y$. Hence

$$
d(x, y)=\lim _{k \rightarrow \infty} d\left(x, T x_{n_{k}}\right)=d(A, B)
$$

which implies that $x \in A_{0}$. Therefore $T$ has the $R J$-property.

Lemma 2.4 Let $T: A \rightarrow B$ be a triangular $\alpha$-proximal admissible mapping. Assume that $\left\{x_{n}\right\}$ is a sequence in $A$ such that $\alpha\left(x_{n+1}, x_{n}\right) \geq 1$, for all $n \in \mathbb{N}$. Then we have $\alpha\left(x_{n}, x_{m}\right) \geq 1$ for all $m, n \in \mathbb{N}$ with $n<m$.

Proof Let $n<m$ and $m=n+k$. For $k=1$, obviously we have $\alpha\left(x_{n}, x_{m}\right) \geq 1$. Let $k>1$. Then

$$
\alpha\left(x_{n}, x_{n+1}\right) \geq 1 \quad \text { and } \quad \alpha\left(x_{n+1}, x_{n+2}\right) \geq 1
$$

Since $T$ is a triangular $\alpha$-admissible mapping, $\alpha\left(x_{n}, x_{n+2}\right) \geq 1$. If $k=2$, the proof is complete. Otherwise for $k>2$ by continuing in this process we can complete the proof.

Definition 2.5 Let $A$ and $B$ be two nonempty subsets of metric space $(X, d)$, and $\alpha: X \times$ $X \rightarrow[0, \infty)$ be a function. A mapping $T: A \rightarrow B$ is said to be a generalized $\alpha-\phi$-Geraghty proximal contraction if there exists $\beta \in \mathcal{F}$ such that for all $x, y, u, v \in A$,

$$
\left.\begin{array}{l}
d(u, T x)=d(A, B) \\
d(v, T y)=d(A, B)
\end{array}\right\} \quad \Longrightarrow \quad \alpha(x, y) \phi(d(u, v)) \leq \beta(\phi(M(x, y, u, v))) \phi(M(x, y, u, v))
$$

where

$$
M(x, y, u, v)=\max \{d(x, y), d(x, u), d(y, v)\}, \quad \text { for any } x, y, u, v \in A
$$

and $\phi \in \Phi$.

Now we prove the following theorem, which extends, improves, and generalizes some earlier results in the literature on best proximity point theorems.

Theorem 2.6 Let $A$ and $B$ be two nonempty subsets of the complete metric space $(X, d)$, $\alpha: X \times X \rightarrow \mathbb{R}$ be a function, and let $T: A \rightarrow B$ be a mapping. Suppose that the following conditions are satisfied: 
(i) $T$ is a generalized $\alpha-\phi$-Geraghty proximal contraction type mapping;

(ii) $T\left(A_{0}\right) \subseteq B_{0}$ and $T$ is triangular $\alpha$-proximal admissible;

(iii) $T$ has the RJ-property;

(iv) if $\left\{x_{n}\right\}$ is a sequence in $A$ such that $\alpha\left(x_{n}, x_{n+1}\right) \geq 1$ for all $n$ and $x_{n} \rightarrow x \in A$ as $n \rightarrow \infty$, then there exists a subsequence $\left\{x_{n_{k}}\right\}$ of $\left\{x_{n}\right\}$ such that $\alpha\left(x_{n_{k}}, x\right) \geq 1$ for all $k$;

(v) there exist $x_{0}, x_{1} \in A$ such that

$$
d\left(x_{1}, T x_{0}\right)=d(A, B) \quad \text { and } \quad \alpha\left(x_{0}, x_{1}\right) \geq 1
$$

Then there exists an element $x^{*} \in A_{0}$ such that

$$
d\left(x^{*}, T x^{*}\right)=d(A, B) .
$$

Moreover, if $\alpha(x, y) \geq 1$ for all $x, y \in P_{T}(A)$, then $x^{*}$ is the unique best proximity point of $T$.

Proof Let $x_{1}, x_{0} \in A$ be such that

$$
d\left(x_{1}, T x_{0}\right)=d(A, B) \quad \text { and } \quad \alpha\left(x_{0}, x_{1}\right) \geq 1
$$

Therefore $x_{1} \in A_{0}$. Since $T\left(A_{0}\right) \subseteq B_{0}$, there exists $x_{2} \in A_{0}$ such that $d\left(x_{2}, T x_{1}\right)=d(A, B)$. Now, we have

$$
\left\{\begin{array}{l}
\alpha\left(x_{0}, x_{1}\right) \geq 1 \\
d\left(x_{1}, T x_{0}\right)=d(A, B), \\
d\left(x_{2}, T x_{1}\right)=d(A, B) .
\end{array}\right.
$$

Since $T$ is $\alpha$-proximal admissible, $\alpha\left(x_{2}, x_{1}\right) \geq 1$. Thus, we have

$$
d\left(x_{2}, T x_{1}\right)=d(A, B) \quad \text { and } \quad \alpha\left(x_{1}, x_{2}\right) \geq 1 .
$$

Continuing this process, by induction, we can construct a sequence $\left\{x_{n}\right\} \subseteq A_{0}$ such that

$$
d\left(x_{n+1}, T x_{n}\right)=d(A, B) \quad \text { and } \quad \alpha\left(x_{n}, x_{n+1}\right) \geq 1, \quad \text { for all } n \in \mathbb{N} .
$$

Therefore for any $n \in \mathbb{N}$, we have

$$
\left\{\begin{array}{l}
\alpha\left(x_{n-1}, x_{n}\right) \geq 1, \\
d\left(x_{n}, T x_{n-1}\right)=d(A, B), \\
d\left(x_{n+1}, T x_{n}\right)=d(A, B) .
\end{array}\right.
$$

Since $T$ is a generalized $\alpha-\phi$-Geraghty proximal contraction type mapping, we have

$$
\begin{aligned}
\phi\left(d\left(x_{n}, x_{n+1}\right)\right) & \leq \alpha\left(x_{n-1}, x_{n}\right) \phi\left(d\left(x_{n}, x_{n+1}\right)\right) \\
& \leq \beta\left(M\left(x_{n-1}, x_{n}, x_{n}, x_{n+1}\right)\right) \phi\left(M\left(x_{n-1}, x_{n}, x_{n}, x_{n+1}\right)\right) \\
& <\phi\left(M\left(x_{n-1}, x_{n}, x_{n}, x_{n+1}\right)\right) .
\end{aligned}
$$


Also we have

$$
\begin{aligned}
M\left(x_{n-1}, x_{n}, x_{n}, x_{n+1}\right) & =\max \left\{d\left(x_{n-1}, x_{n}\right), d\left(x_{n-1}, x_{n}\right), d\left(x_{n}, x_{n+1}\right)\right\} \\
& =\max \left\{d\left(x_{n-1}, x_{n}\right), d\left(x_{n}, x_{n+1}\right)\right\} .
\end{aligned}
$$

If $M\left(x_{n-1}, x_{n}, x_{n}, x_{n+1}\right)=d\left(x_{n}, x_{n+1}\right)$, applying (2.2), we deduce that

$$
\begin{aligned}
\phi\left(d\left(x_{n}, x_{n+1}\right)\right) & <\phi\left(M\left(x_{n-1}, x_{n}, x_{n}, x_{n+1}\right)\right) \\
& =\phi\left(d\left(x_{n}, x_{n+1}\right)\right),
\end{aligned}
$$

which is a contradiction. Thus, we conclude that

$$
M\left(x_{n-1}, x_{n}, x_{n}, x_{n+1}\right)=d\left(x_{n-1}, x_{n}\right), \quad \forall n \in \mathbb{N} .
$$

Now, from (2.2) and (2.3), we get

$$
\phi\left(d\left(x_{n}, x_{n+1}\right)\right)<\phi\left(d\left(x_{n-1}, x_{n}\right)\right), \quad \forall n \in \mathbb{N} .
$$

Regarding the properties of $\phi$, implies that

$$
d\left(x_{n}, x_{n+1}\right)<d\left(x_{n-1}, x_{n}\right), \quad \forall n \in \mathbb{N} .
$$

Hence, we deduce that the sequence $\left\{d\left(x_{n}, x_{n+1}\right)\right\}$ is nonnegative and decreasing. Consequently, there exists $r \geq 0$ such that $\lim _{n \rightarrow \infty} d\left(x_{n}, x_{n+1}\right)=r$.

Suppose that there exists $n_{0} \in \mathbb{N}$ such that $d\left(x_{n_{0}}, x_{n_{0}+1}\right)=0$. This implies that $x_{n_{0}}=x_{n_{0}+1}$. Applying (2.1), we deduce that

$$
d\left(x_{n_{0}}, T x_{n_{0}}\right)=d\left(x_{n_{0}+1}, T x_{n_{0}}\right)=d(A, B) .
$$

This is the desired result. Now let, for any $n \in \mathbb{N}, d\left(x_{n}, x_{n+1}\right) \neq 0$. In the sequel, we prove that $r=0$. In the contrary case suppose that $r>0$. Then from (2.2) and (2.3), we have

$$
0<\frac{\phi\left(d\left(x_{n}, x_{n+1}\right)\right)}{\phi\left(d\left(x_{n-1}, x_{n}\right)\right)} \leq \beta\left(\phi\left(d\left(x_{n-1}, x_{n}\right)\right)\right),
$$

which implies that $\lim _{n \rightarrow \infty} \beta\left(\phi\left(d\left(x_{n-1}, x_{n}\right)\right)\right)=1$. Since $\beta \in \mathcal{F}$,

$$
\lim _{n \rightarrow \infty} \phi\left(d\left(x_{n-1}, x_{n}\right)\right)=0 .
$$

This implies that $r=0$, which is a contradiction. Therefore $\lim _{n \rightarrow \infty} d\left(x_{n}, x_{n+1}\right)=0$. Now, we shall prove that $\left\{x_{n}\right\}$ is a Cauchy sequence in the metric space $(X, d)$. Note that for any $m, n \in \mathbb{N}$, we have

$$
\left\{\begin{array}{l}
\alpha\left(x_{n}, x_{m}\right) \geq 1, \\
d\left(x_{n+1}, T x_{n}\right)=d(A, B), \\
d\left(x_{m+1}, T x_{m}\right)=d(A, B) .
\end{array}\right.
$$


Then, for any $m, n \in \mathbb{N}$, we have

$$
\begin{aligned}
\phi\left(d\left(x_{n+1}, x_{m+1}\right)\right) & \leq \alpha\left(x_{n}, x_{m}\right) \phi\left(d\left(x_{n+1}, x_{m+1}\right)\right) \\
& \leq \beta\left(\phi\left(M\left(x_{n}, x_{m}, x_{n+1}, x_{m+1}\right)\right)\right) \phi\left(M\left(x_{n}, x_{m}, x_{n+1}, x_{m+1}\right)\right) .
\end{aligned}
$$

Also for any $m, n \in \mathbb{N}$, we have

$$
M\left(x_{n}, x_{m}, x_{n+1}, x_{m+1}\right)=\max \left\{d\left(x_{n}, x_{m}\right), d\left(x_{n}, x_{n+1}\right), d\left(x_{m}, x_{m+1}\right)\right\} .
$$

Since $\lim _{n \rightarrow \infty} d\left(x_{n}, x_{n+1}\right)=0$,

$$
\limsup _{m, n \rightarrow \infty} M\left(x_{n}, x_{m}, x_{n+1}, x_{m+1}\right)=\limsup _{m, n \rightarrow \infty} d\left(x_{n}, x_{m}\right) .
$$

In the following, we show that $\left\{x_{n}\right\}$ is a Cauchy sequence. In the contrary case, we have

$$
\limsup _{m, n \rightarrow \infty} d\left(x_{n}, x_{m}\right)=r>0 .
$$

By using the triangular inequality and taking the limit as $n \rightarrow \infty$, we derive

$$
\begin{aligned}
\limsup _{m, n \rightarrow \infty} d\left(x_{n}, x_{m}\right) & \leq \limsup _{m, n \rightarrow \infty}\left(d\left(x_{n}, x_{n+1}\right)+d\left(x_{n+1}, x_{m+1}\right)+d\left(x_{m+1}, x_{m}\right)\right) \\
& =\limsup _{m, n \rightarrow \infty} d\left(x_{n+1}, x_{m+1}\right) .
\end{aligned}
$$

Combining (2.4), (2.5), and (2.6) with the continuity of $\phi$, we get

$$
\limsup _{m, n \rightarrow \infty} \phi\left(d\left(x_{n}, x_{m}\right)\right) \leq \limsup _{m, n \rightarrow \infty} \beta\left(\phi\left(M\left(x_{n}, x_{m}, x_{n+1}, x_{m+1}\right)\right)\right) \limsup _{m, n \rightarrow \infty} \phi\left(d\left(x_{n}, x_{m}\right)\right) .
$$

Since $\lim \sup _{m, n \rightarrow \infty} d\left(x_{n}, x_{m}\right)=r>0$, we deduce that

$$
\limsup _{m, n \rightarrow \infty} \beta\left(\phi\left(M\left(x_{n}, x_{m}, x_{n+1}, x_{m+1}\right)\right)\right)=1 .
$$

By taking the fact $\beta \in \mathcal{F}$, we get

$$
\limsup _{m, n \rightarrow \infty} d\left(x_{n}, x_{m}\right)=\limsup _{m, n \rightarrow \infty} M\left(x_{n}, x_{m}, x_{n+1}, x_{m+1}\right)=0
$$

which is a contradiction. Therefore, $\left\{x_{n}\right\}$ is a Cauchy sequence. Since $\left\{x_{n}\right\}$ is a sequence in complete metric space $(X, d)$, there exists $x^{*} \in X$ such that $\lim _{n \rightarrow \infty} x_{n}=x^{*} . R J$-property of $T$, implies that $x^{*} \in A_{0}$. Since $T\left(A_{0}\right) \subseteq B_{0}$, there exists $w \in A_{0}$ such that $d\left(w, T x^{*}\right)=d(A, B)$. We shall prove that $w=x^{*}$. In the contrary case let $w \neq x^{*}$.

Property (iv) implies that there exists a subsequence $\left\{x_{n_{k}}\right\}$ of $\left\{x_{n}\right\}$ such that $\alpha\left(x_{n_{k}}, x\right) \geq$ 1 for all $k \in \mathbb{N}$. Without loss of generality, we assume that

$$
\alpha\left(x_{n}, x^{*}\right) \geq 1, \quad \text { for all } n \in \mathbb{N} \text {. }
$$


For any $n \in \mathbb{N}$, we have $d\left(x_{n+1}, T x_{n}\right)=d(A, B)$ and $d\left(w, T x^{*}\right)=d(A, B)$. Using the fact that $T$ is a generalized $\alpha-\phi$-Geraghty proximal contraction type mapping, for any $n \in \mathbb{N}$, we have

$$
\begin{aligned}
\phi\left(d\left(x_{n+1}, w\right)\right) & \leq \alpha\left(x_{n}, x^{*}\right) \phi\left(d\left(x_{n+1}, w\right)\right) \\
& \leq \beta\left(\phi\left(M\left(x_{n}, x^{*}, x_{n+1}, w\right)\right)\right) \phi\left(M\left(x_{n}, x^{*}, x_{n+1}, w\right)\right) \\
& <\phi\left(M\left(x_{n}, x^{*}, x_{n+1}, w\right)\right) .
\end{aligned}
$$

Also for any $n \in \mathbb{N}$, we have

$$
M\left(x_{n}, x^{*}, x_{n+1}, w\right)=\max \left\{d\left(x_{n}, x^{*}\right), d\left(x_{n}, x_{n+1}\right), d\left(x^{*}, w\right)\right\} .
$$

Let there exist a subsequence $\left\{x_{n_{k}}\right\} \subseteq\left\{x_{n}\right\}$ such that

$$
M\left(x_{n_{k}}, x^{*}, x_{n_{k}+1}, w\right)=d\left(x^{*}, w\right), \quad \forall k \in \mathbb{N} .
$$

Thus for any $k \in \mathbb{N}$, we have

$$
\phi\left(d\left(x_{n_{k}+1}, w\right)\right) \leq \alpha\left(x_{n_{k}}, x^{*}\right) \phi\left(d\left(x_{n_{k}+1}, w\right)\right) \leq \beta\left(\phi\left(d\left(x^{*}, w\right)\right)\right) \phi\left(d\left(x^{*}, w\right)\right) .
$$

Taking the limit of both sides as $n \rightarrow \infty$, implies that $\beta\left(\phi\left(d\left(x^{*}, w\right)\right)\right)=1$, which is a contradiction. Thus there exists $k \in \mathbb{N}$ such that

$$
M\left(x_{n}, x^{*}, x_{n+1}, w\right)=\max \left\{d\left(x_{n}, x^{*}\right), d\left(x_{n}, x_{n+1}\right)\right\}, \quad \forall n>k .
$$

From this, together with (2.7), (2.8), and by taking the limit as $n \rightarrow \infty$, we deduce that $d\left(x^{*}, w\right)=0$. This is a contradiction. Therefore $x^{*}=w$, which implies that

$$
d\left(x^{*}, T x^{*}\right)=d\left(w, T x^{*}\right)=d(A, B) .
$$

Hence $x^{*}$ is the best proximity point of $T$.

For the uniqueness, let $\alpha(x, y) \geq 1$ for all $x, y \in P_{T}(A)$. Suppose that $x_{1}$ and $x_{2}$ are two best proximity points of $T$ with $x_{1} \neq x_{2}$. Therefore

$$
\left\{\begin{array}{l}
d\left(x_{1}, T x_{1}\right)=d(A, B), \\
d\left(x_{2}, T x_{2}\right)=d(A, B) .
\end{array}\right.
$$

Also, we have

$$
M\left(x_{1}, x_{2}, x_{1}, x_{2}\right)=\max \left\{d\left(x_{1}, x_{2}\right), d\left(x_{1}, x_{1}\right), d\left(x_{2}, x_{2}\right)\right\}=d\left(x_{1}, x_{2}\right)
$$

Since $\alpha\left(x_{1}, x_{2}\right) \geq 1$ and $T$ is a generalized $\alpha-\phi$-Geraghty proximal contraction type mapping, we get

$$
\begin{aligned}
\phi\left(d\left(x_{1}, x_{2}\right)\right) & \leq \alpha\left(x_{1}, x_{2}\right) \phi\left(d\left(x_{1}, x_{2}\right)\right) \\
& \leq \beta\left(\phi\left(d\left(x_{1}, x_{2}\right)\right)\right) \phi\left(d\left(x_{1}, x_{2}\right)\right)<\phi\left(d\left(x_{1}, x_{2}\right)\right)
\end{aligned}
$$

which is a contradiction. Hence the best proximity point is unique. 
If in Theorem 2.6 we take $\phi(t)=t$ for all $t \geq 0$, then we deduce the following corollary.

Corollary 2.7 Let $A$ and $B$ be two nonempty closed subsets of the complete metric space $(X, d), \alpha: X \times X \rightarrow \mathbb{R}$ be a function, and let $T: A \rightarrow B$ be a mapping. Suppose that the following conditions are satisfied:

(i) $T$ is a generalized $\alpha$-Geraghty proximal contraction type mapping, that is,

$$
\left.\begin{array}{l}
d(u, T x)=d(A, B) \\
d(v, T y)=d(A, B)
\end{array}\right\} \quad \Longrightarrow \quad \alpha(x, y) d(u, v) \leq \beta(M(x, y, u, v)) M(x, y, u, v)
$$

where $M(x, y, u, v)=\max \{d(x, y), d(x, u), d(y, v)\}$, for any $x, y, u, v \in A$.

(ii) The conditions (ii), (iii), (iv) and (v) of Theorem 2.6 are satisfied.

Then there exists an element $x^{*} \in A_{0}$ such that

$$
d\left(x^{*}, T x^{*}\right)=d(A, B)
$$

Moreover, if $\alpha(x, y) \geq 1$ for all $x, y \in P_{T}(A)$, then $x^{*}$ is the unique best proximity point of $T$.

By Example 2.2 a continuous map has the $R J$-property and if all conditions of Theorem 2.6 are satisfied, then $T$ has a best proximity point. In the next theorem, we prove that in Theorem 2.6, if mapping $T$ is continuous, then condition (iv) is not needed.

Theorem 2.8 Let $A, B$ be two nonempty subsets of the complete metric space $(X, d), \alpha$ : $X \times X \rightarrow \mathbb{R}$ be a function, and let $T: A \rightarrow B$ be a mapping. Suppose that the following conditions are satisfied:

(i) The conditions (i), (ii) and (v) of Theorem 2.6 are satisfied;

(ii) $T$ is continuous.

Then there exists an element $x^{*} \in A_{0}$ such that

$$
d\left(x^{*}, T x^{*}\right)=d(A, B) .
$$

Moreover, if $\alpha(x, y) \geq 1$ for all $x, y \in P_{T}(A)$, then $x^{*}$ is the unique best proximity point of $T$.

Proof Let $x_{0}, x_{1} \in A$ be such that

$$
d\left(x_{1}, T x_{0}\right)=d(A, B) \quad \text { and } \quad \alpha\left(x_{0}, x_{1}\right) \geq 1 .
$$

Therefore $x_{1} \in A_{0}$. Since $T\left(A_{0}\right) \subseteq B_{0}$, there exists $x_{2} \in A_{0}$ such that $d\left(x_{2}, T x_{1}\right)=d(A, B)$. Now, we have

$$
\left\{\begin{array}{l}
\alpha\left(x_{0}, x_{1}\right) \geq 1 \\
d\left(x_{1}, T x_{0}\right)=d(A, B) \\
d\left(x_{2}, T x_{1}\right)=d(A, B)
\end{array}\right.
$$

Since $T$ is $\alpha$-proximal admissible, $\alpha\left(x_{1}, x_{2}\right) \geq 1$. Thus, we have

$$
d\left(x_{2}, T x_{1}\right)=d(A, B) \quad \text { and } \quad \alpha\left(x_{1}, x_{2}\right) \geq 1 .
$$


Continuing this process, by induction, we can construct a sequence $\left\{x_{n}\right\} \subseteq A_{0}$ such that

$$
d\left(x_{n+1}, T x_{n}\right)=d(A, B) \quad \text { and } \quad \alpha\left(x_{n}, x_{n+1}\right) \geq 1, \quad \text { for all } n \in \mathbb{N} .
$$

Following the lines in the proof of Theorem 2.6, there exists a sequence $\left\{x_{n}\right\}$ such that $d\left(x_{n+1}, T x_{n}\right)=d(A, B)$ for all $n$, and the sequence $\left\{x_{n}\right\}$ converges to some $x^{*} \in A$. Since $T$ is continuous, obviously

$$
d\left(x^{*}, T x^{*}\right)=\lim _{n \rightarrow \infty} d\left(x_{n+1}, T x_{n}\right)=d(A, B) .
$$

Therefore $x^{*}$ is the best proximity point of $T$. If $\alpha(x, y) \geq 1$ for all $x, y \in P_{T}(A)$, following the lines in the proof of Theorem 2.6, we see that the best proximity point is unique.

To illustrate our results given in Theorem 2.6, we present the following example, which shows that Theorem 2.6 is a proper generalization of Corollary 2.7.

Example 2.9 Consider $X=\mathbb{R}^{2}$ with the usual metric. Let $A$ and $B$ be the subsets of $X$ defined by

$$
A=\{0\} \times\{\mathbb{Q} \cap[0,5]\} \text { and } B=\{1\} \times[0,5] .
$$

Obviously, $d(A, B)=1$. Moreover, it is easily seen that $A_{0}=A$. Let $T: A \rightarrow B$ be the mapping defined as

$$
T(0, x)=\left(1, \frac{4}{5} \ln (1+x)\right), \quad \text { for all }(0, x) \in A .
$$

Also define $\alpha: X \times X \rightarrow \mathbb{R}$ by

$$
\alpha(x, y)= \begin{cases}1, & x, y \in A \\ 0, & \text { otherwise }\end{cases}
$$

In the sequel, we check that $T$ is a generalized $\alpha-\phi$-Geraghty proximal contraction type mapping. Define $\beta:[0, \infty) \rightarrow[0,1)$ and $\phi:[0, \infty) \rightarrow[0, \infty)$ by

$$
\beta(t)=\frac{\arctan t}{t} \quad \text { and } \quad \phi(t)=\frac{1}{2} t^{3}, \quad \text { for all } t \geq 0 .
$$

Then $\beta \in \mathcal{F}, \phi \in \Phi$. Let $x, y \in A$. Then $t=d(x, y) \in[0,5]$. Also, it is easy to show that

$$
\frac{1}{2}\left(\frac{4}{5} \ln (1+t)\right)^{3} \leq \arctan \left(\frac{1}{2} t^{3}\right), \quad \text { for all } t \in[0,5]
$$

Let $x=\left(0, x_{0}\right), y=\left(0, y_{0}\right), u=\left(0, u_{0}\right), v=\left(0, v_{0}\right) \in A$ satisfied the following conditions:

$$
\left\{\begin{array}{l}
d(u, T x)=d(A, B), \\
d(v, T y)=d(A, B) .
\end{array}\right.
$$


Then $u_{0}=\frac{4}{5} \ln \left(x_{0}+1\right)$ and $v_{0}=\frac{4}{5} \ln \left(y_{0}+1\right)$. Since $f(t)=\arctan \left(\frac{1}{2} t^{3}\right)$ is a nondecreasing function, from (2.9), we have

$$
\begin{aligned}
\alpha(x, y) \phi(d(u, v)) & =\frac{1}{2}\left(\frac{4}{5}\left|\ln \left(\frac{1+x_{0}}{1+y_{0}}\right)\right|\right)^{3} \\
& \leq \frac{1}{2}\left(\frac{4}{5} \ln \left(1+\left|x_{0}-y_{0}\right|\right)\right)^{3} \\
& \leq \arctan \left(\frac{1}{2}\left(\left|x_{0}-y_{0}\right|\right)^{3}\right) \\
& =\arctan \left(\frac{1}{2} d(x, y)^{3}\right) \\
& \leq \arctan \left(\frac{1}{2}(M(x, y, u, v))^{3}\right) \\
& =\beta(\phi(M(x, y, u, v))) \phi(M(x, y, u, v)) .
\end{aligned}
$$

Hence $T$ is a generalized $\alpha-\phi$-Geraghty proximal contraction type mapping. Obviously, the other conditions of Theorem 2.6 are satisfied. Therefore $T$ has an unique best proximity point.

Note that $x^{*}=(0,0)$ is the best proximity point of $T$.

Applying Example 2.3 and Theorem 2.6 we have the following corollary.

Corollary 2.10 Let $A, B$ be two nonempty subsets of the complete metric space $(X, d), \alpha$ : $X \times X \rightarrow \mathbb{R}$ be a function, and let $T: A \rightarrow B$ be a mapping. Suppose that the following conditions are satisfied:

(i) The conditions (i), (ii), (iv) and (v) of Theorem 2.6 are satisfied;

(ii) $B$ is approximatively compact with respect to $A$.

Then there exists an element $x^{*} \in A_{0}$ such that

$$
d\left(x^{*}, T x^{*}\right)=d(A, B) .
$$

Moreover, if $\alpha(x, y) \geq 1$ for all $x, y \in P_{T}(A)$, then $x^{*}$ is the unique best proximity point of $T$.

\section{Applications in fixed point theory}

As applications of our results, we prove some new fixed point theorems as follows. We start with the following fixed point theorem which is proved by Karapinar in [8].

Theorem 3.1 Let $(X, d)$ be a complete metric space, $\alpha: X \times X \rightarrow \mathbb{R}$ be a function, and let $T: X \rightarrow X$ be a map. Suppose that the following conditions are satisfied:

(i) $T$ is generalized $\alpha$ - $\phi$-Geraghty contraction type map;

(ii) $T$ is triangular $\alpha$-admissible;

(iii) there exists $x_{0} \in X$ such that $\alpha\left(x_{0}, T x_{0}\right) \geq 1$;

(iv) either, $T$ is continuous, or $\left\{x_{n}\right\}$ is $\alpha$-regular.

Then $T$ has a fixed point $x^{*} \in X$, and $\left\{T^{n} x_{0}\right\}$ converges to $x^{*}$. 
Proof Let $A=B=X$. First, we prove that $T$ is a generalized $\alpha-\phi$-Geraghty proximal contraction type map. Let $x, y, u, v \in X$, satisfy the following conditions:

$$
\left\{\begin{array}{l}
d(u, T x)=d(A, B), \\
d(v, T y)=d(A, B) .
\end{array}\right.
$$

Since $d(A, B)=0$, we have $u=T x$ and $v=T y . T$ is a generalized $\alpha-\phi$-Geraghty contraction mapping, which implies that

$$
\alpha(x, y) \phi(d(u, v))=\alpha(x, y) \phi(d(T x, T y)) \leq \beta(\phi(M(x, y))) \phi(M(x, y)) .
$$

Also,

$$
M(x, y)=\max \{d(x, y), d(x, T x), d(y, T y)\}=\max \{d(x, y), d(x, u), d(y, v)\}=M(x, y, u, v) .
$$

Therefore

$$
\alpha(x, y) \phi(d(u, v)) \leq \beta(\phi(M(x, y, u, v))) \phi(M(x, y, u, v)),
$$

which implies that $T$ is a generalized $\alpha-\phi$-Geraghty proximal contraction type map. Let

$$
\left\{\begin{array}{l}
\alpha(x, y) \geq 1, \\
d(u, T x)=d(A, B), \\
d(v, T y)=d(A, B) .
\end{array}\right.
$$

Then $\alpha$-admissible property of $T$ implies that $\alpha(u, v)=\alpha(T x, T y) \geq 1$. Therefore $T$ is a triangular $\alpha$-proximal admissible mapping. Applying condition (iii), there exists $x_{0} \in X$ such that $\alpha\left(x_{0}, T x_{0}\right) \geq 1$.

If $x_{1}=T x_{0}$, then

$$
\alpha\left(x_{0}, x_{1}\right) \geq 1 \quad \text { and } \quad d\left(x_{1}, T x_{0}\right)=d\left(T x_{0}, T x_{0}\right)=d(A, B) .
$$

Since the pair $(A, B)$ has the $R J$-property, the conditions of Theorem 2.6 are satisfied, and so there exists $x^{*} \in X$ such that $d\left(x^{*}, T x^{*}\right)=0$, which implies that $T x^{*}=x^{*}$.

Remark 3.2 The fixed point of a generalized $\alpha-\phi$-Geraghty contraction mapping is unique if it satisfies the following condition:

$\left(H_{1}\right)$ For all $x, y \in \operatorname{Fix}(T)$, there exists $z \in X$ such that $\alpha(x, z) \geq 1$ and $\alpha(z, y) \geq 1$.

Note that triangular $\alpha$-admissible property of $T$ and condition $\left(H_{1}\right)$ imply that

$$
\alpha(x, y) \geq 1, \quad \text { for all } x, y \in P_{T}(A) .
$$

Now, applying Theorems 2.6 and 2.8, the fixed point is unique.

Let $\phi(t)=t$. Then we have the following definition and corollary. 
Definition 3.3 ([14]) Let $(X, d)$ be a metric space and $\alpha: X \times X \rightarrow \mathbb{R}$ be a function. A map $T: X \rightarrow X$ is said to be generalized $\alpha$-Geraghty contraction type map if there exists $\beta \in \mathcal{F}$ such that

$$
\alpha(x, y) d(T x, T y) \leq \beta(M(x, y)) M(x, y), \quad \forall x, y \in X,
$$

where

$$
M(x, y)=\max \{d(x, y), d(x, T x), d(y, T y)\}
$$

Corollary 3.4 ([14]) Let $(X, d)$ be a complete metric space, $\alpha: X \times X \rightarrow \mathbb{R}$ be a function, and let $T: X \rightarrow X$ be a map. Suppose that the following conditions are satisfied:

(i) $T$ is generalized $\alpha$-Geraghty contraction map;

(ii) $T$ is triangular $\alpha$-admissible;

(iii) there exists $x_{0} \in X$ such that $\alpha\left(x_{0}, T x_{0}\right) \geq 1$;

(iv) either, $T$ is continuous, or $\left\{x_{n}\right\}$ is $\alpha$-regular.

Then $T$ has a fixed point $x^{*} \in X$, and $\left\{T^{n} x_{0}\right\}$ converges to $x^{*}$.

Further, iffor all $x, y \in \operatorname{Fix}(T)$, there exists $z \in X$ such that $\alpha(x, z) \geq 1$ and $\alpha(z, y) \geq 1$, and so fixed point of $T$ is unique.

\section{Competing interests}

The authors declare that they have no competing interests.

\section{Authors' contributions}

All authors contributed equally and significantly in writing this article. All authors read and approved the final manuscript.

Received: 26 November 2015 Accepted: 14 June 2016 Published online: 29 June 2016

\section{References}

1. Eldred, AA, Veeramani, P: Existence and convergence of best proximity points. J. Math. Anal. Appl. 323(2), 1001-1006 (2006)

2. Bilgili, N, Karapınar, E, Sadarangani, K: A generalization for the best proximity point of Geraghty-contractions. J. Inequal. Appl. 2013, 286 (2013)

3. Geraghty, M: On contractive mappings. Proc. Am. Math. Soc. 40, 604-608 (1973)

4. Sankar Raj, VS: A best proximity point theorem for weakly contractive non-self-mappings. Nonlinear Anal. 74(14), 4804-4808 (2011)

5. Chuadchawna, P, Kaewcharoen, A, Plubtieng, S: Fixed point theorems for generalized $\alpha-\eta$ - $\psi$-Geraghty contraction type mappings in $\alpha-\eta$-complete metric spaces. J. Nonlinear Sci. Appl. 9, 471-485 (2016)

6. Abkar, A, Gabeleh, M: Global optimal solutions of noncyclic mappings in metric spaces. J. Optim. Theory Appl. 153(2), 298-305 (2012)

7. Gabeleh, M: Best proximity point theorems via proximal non-self mappings. J. Optim. Theory Appl. 164(2), 565-576 (2015)

8. Karapınar, E: A discussion on ' $\alpha$ - $\psi$-Geraghty contraction type mappings'. Filomat 28(4), 761-766 (2014)

9. Samet, B, Vetro, C, Vetro, P: Fixed point theorems for $\alpha$ - $\psi$-contractive type mappings. Nonlinear Anal. 75(4), 2154-2165 (2012)

10. Jleli, M, Samet, B: Best proximity points for $\alpha$ - $\psi$-proximal contractive type mappings and applications. Bull. Sci. Math 137(8), 977-995 (2013)

11. Karapinar, E: On best proximity point of $\psi$-Geraghty contractions. Fixed Point Theory Appl. 2013, 200 (2013)

12. Jleli, M, Karapınar, E, Samet, B: Best proximity point for generalized $\alpha$ - $\phi$-proximal contraction type mappings. J. Appl. Math. 2013, 534127 (2013)

13. Karapınar, E, Samet, B: Generalized $\alpha-\psi$ contractive type mappings and related fixed point theorems with applications. Abstr. Appl. Anal. 2012, Article ID 793486 (2012)

14. Cho, SH, Bae, JS, Karapınar, E: Fixed point theorems for $\alpha$-Geraghty contraction type maps in metric spaces. Fixed Point Theory Appl. 2013, 329 (2012) 